\title{
Fenótipo da gordura, fatores associados e o polimorfismo rs9939609 do gene FTO
}

\author{
Fat phenotype, associated factors and rs9939609 polymorphism \\ of the FTO gene
}

William Alves Lima ${ }^{1}$ Maria Fátima Glaner ${ }^{1}$ Aline Pic Taylor 2

1 Universidade Católica de Brasília, Brasília - DF, Brasil

2 Universidade de Brasília, Brasília - DF, Brasil

Recebido em 11/09/09 Aprovado em 11/12/09
Resumo - O propósito deste foi sintetizar os principais resultados de estudos que analisaram a relação do polimorfismo de nucleotídeo simples (SNP) rs9939609 do gene FTO (fat mass and obesity associated), com a manifestação de sobrepeso / obesidade e suas co-morbidades e discutir a interação deste polimorfismo com os demais fatores promotores da obesidade. A busca foi realizada nas bases de dados MEDLINE, Highwire, Science Direct e SciELO, usando as palavras-chave: FTO rs9939609, obesity genetic, gene associated obesity, FTO contributes obesity. Os critérios de inclusão foram: artigos originais que envolveram seres humanos e que incluíram o rs9939609. Foram excluídos os artigos que analisaram o gene FTO em grupos com doenças hormonais pré-instaladas. Dos vários SNPs contidos no gene FTO, o rs9939609 tem sido o mais pesquisado. Este SNP é composto pelos alelos A e T, sendo os homozigotos A os mais susceptíveis ao desenvolvimento de sobrepeso / obesidade em todas as idades, principalmente, em populações caucasianas. Nessa situação, o controle dos fatores ambientais (alimentação e atividade física) pode prevenir o acúmulo excessivo de gordura. A obesidade está relacionada ao desenvolvimento de doenças crônicas não-transmissíveis. Foram observadas associações do rs9939609 com o perfil lipídico sanguíneo e a glicemia. A prática de exercícios físicos e a alimentação parecem ser os principais influenciadores no desenvolvimento do sobrepeso / obesidade e na instalação das co-morbidades associadas. Palavras-chave: Obesidade; Sobrepeso; Estilo de vida; Co-morbidade; Genética.

Abstract - The purpose of this work was to review the main results of studies that have analysed the relationship between the rs9939609 single nucleotide polymorphism (SNP) of the FTO gene and the manifestation of overweight/obesity with its associated co-morbidity, and to discuss the interaction of this polymorphism with the other factors which cause obesity. The search was performed using the MEDLINE, Highwire, Science Direct and SciELO databases, applying the following key words: FTO rs9939609, obesity genetic, gene associated obesity, FTO contributes obesity. Inclusion criteria were: original articles where the search was performed in humans and including the rs9939609. Articles that analysed the FTO gene associated with preinstalled hormonal diseases were excluded. Of the several SNP associated with the FTO gene, rs 9939609 has been the most researched (studied). This SNP comprises the A and T alleles, with the A homozygote being most susceptible to the development of overweight/obesity in all age ranges, especially in the caucasian population. In this situation, the control of environmental factors (alimentation and physical activity) can prevent the excessive build up of fats. Obesity is related to the development of non-transmissible chronic illnesses. Association of rs 9939609 polymorphism with the lipidic profile and glycemia were observed. The practicing of physical exercise and feeding habits seem to be the main contributors in the development of overweight/ obesity and its resulting co-morbidity.

Key words: Obesity; Overweight; Life Style; Co-Morbidity; Genetic. 


\section{INTRODUÇÃO}

A obesidade é caracterizada pelo acúmulo excessivo de gordura corporal, podendo ter início em qualquer fase da vida ${ }^{1}$. Nas últimas décadas, a sua prevalência aumentou significativamente em todas as faixas etárias, tornando-se uma epidemia global ${ }^{2,3}$. Concomitantemente ao processo de sua instalação, também pode ocorrer o desenvolvimento de anormalidades metabólicas, como o aumento excessivo de triglicérides, colesterol total, lipoproteínas de baixa densidade e glicemia ${ }^{4,5}$. Assim, a obesidade facilita o desenvolvimento de várias doenças crônicas não-transmissíveis, principalmente, as cardiovasculares $^{6}$ e o diabetes ${ }^{7}$. Consequentemente, combater a obesidade e prevenir a instalação de várias co-morbidades associadas tornou-se uma necessidade de saúde pública ${ }^{1}$. A prevenção seria mais efetiva se fossem conhecidos os genes que podem tornar um indivíduo mais propenso ao armazenamento excessivo de gordura ${ }^{8,9}$.

Ao pesquisar uma possível ação do gene FTO (do inglês: fat mass and obesity associated - associado à massa gorda e obesidade) para o desenvolvimento do diabetes tipo II, Frayling et al. ${ }^{7}$ encontraram, para indivíduos com duas cópias do alelo $\mathrm{A}$, uma chance 1,3 vezes maior de manifestar a doença. Porém, após ajuste estatístico para o índice de massa corporal (IMC) a associação entre o diabetes tipo II e o FTO foi eliminada, sugerindo que esta era mediada pela ocorrência de sobrepeso ou obesidade. Desde então, estudos foram direcionados para averiguar a relação do gene FTO com o acúmulo excessivo de gordura e sua interação com fatores comportamentais.

Considerando a atenção que vem sendo dispensada ao polimorfismo de nucleotídeo simples (SNP - do inglês: single nucleotide polymorphisms) rs9939609 do gene FTO e a divergência entre os resultados encontrados para diversos grupos populacionais, esta revisão foi realizada com a finalidade de sintetizar: os principais resultados de estudos que analisaram a relação do SNP rs9939609 do gene FTO com o acúmulo excessivo de gordura e suas co-morbidades; a interação deste polimorfismo com os demais fatores promotores do sobrepeso e/ ou obesidade.

\section{PROCEDIMENTOS}

A busca por artigos científicos foi feita em periódicos indexados/hospedados nas seguintes bases: MEDLINE, Highwire press Stanford University,
Science Direct e Scientific Electronic Library Online - SciELO. Foram inseridas as palavras chave: FTO rs9939609, obesity genetic, gene associated obesity, FTO contributes obesity. Foram incluídos artigos originais publicados até agosto de 2009, cujas amostras foram compostas por humanos e que englobaram o rs9939609. Foram excluídos os artigos que fugiam à temática em questão e os que pesquisaram o gene FTO em grupos específicos com doenças hormonais pré-instaladas. Algumas referências, que não puderam ser localizadas por meio das palavras-chave mencionadas, foram usadas para fazer alusão ao aumento da obesidade e aos conceitos básicos em genética.

Hoje em dia, a aplicabilidade da genética em estudos ligados às áreas da saúde é incontestável, porém, muitas vezes existe uma dificuldade em compreender totalmente os conceitos desta área específica. Vê-se, então, necessário, antes da abordagem do tema proposto, um esclarecimento sucinto do conhecimento básico em genética e empregado nesta revisão. Posteriormente, são apresentadas as generalidades do gene FTO e do SNP rs9939609, a relação destes com o fenótipo da gordura e co-morbidades associadas e, por último, a influência do estilo de vida sobre o rs9939609 e o fenótipo da gordura.

\section{Conceitos básicos em genética}

A genética é uma ciência que busca compreender a transmissão das características de uma geração para a outra. Em eucariotos o DNA (ácido desoxirribonucleico, do inglês: deoxyribonucleic acid), molécula responsável pela transmissão destas características, está normalmente presente num compartimento celular denominado núcleo ${ }^{10}$. Dentro do núcleo, o DNA está organizado em estruturas chamadas cromossomos (Figura 1). Cada cromossomo possui uma longa molécula de DNA compactada que, por sua vez, é composta por uma dupla fita de nucleotídeos que se mantêm unida graças a ligações fracas, conhecidas como pontes de hidrogênio ${ }^{11}$.

Os nucleotídeos são formados por três elementos: uma base nitrogenada, um fosfato e um açúcar, denominado ribose (Figura 2). A ribose do DNA se distingue daquela encontrada no RNA (ácido ribonucleico, do inglês: ribonucleic acid), por possuir um hidrogênio na posição C2 (carbono), ao invés do grupamento hidroxila, por isso diz-se que o DNA é um acido desoxirribonucléico. Esta modificação colabora para a estabilidade da molécula de $\mathrm{DNA}^{12}$. 


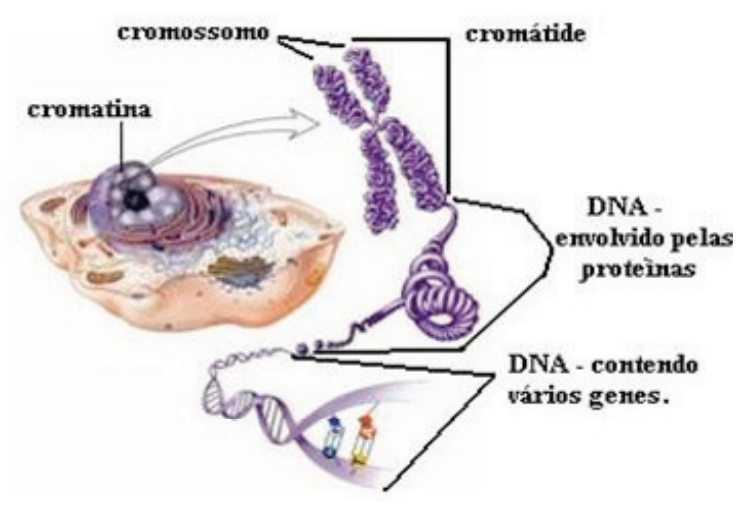

Figura 1. Núcleo contendo cromossomo enovelado, o qual é formado por uma dupla fita de DNA. Figura extraída do Centro de referência virtual do professor ${ }^{11}$.

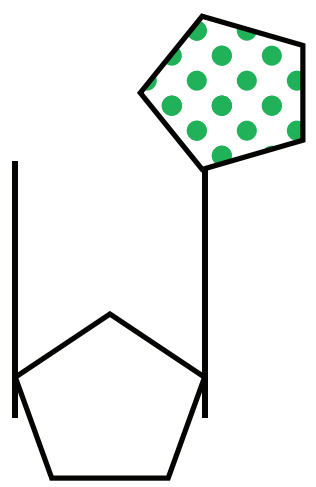

Figura 2. Elementos que constituem o nucleotídeo, fosfato, açúcar e base nitrogenada.

Existem cinco tipos de bases nitrogenadas: Adenina, Timina, Guanina, Citosina e Uracila. Em cada tipo de ácido nucléico, DNA ou RNA, apenas quatro bases são encontradas. Assim, a Timina é somente encontrada no DNA, e a Uracila, somente no RNA. Podem-se classificar as bases nucleotídicas em dois grupos, purinas (adenina e guanina), que possuem dois anéis aromáticos e as pirimidinas (timina, citosina e uracila), que possuem apenas um anel aromático ${ }^{13}$.

Durante a síntese de DNA, a dupla hélice se abre, e cada filamento serve como molde para um novo, assim, pode-se dizer que a síntese de DNA é semi-conservativa, já que cada novo filamento é composto por apenas um dos filamentos da fita mãe, além do recém sintetizado. Esta síntese se faz por complementaridade de bases, de modo que uma purina só pode se ligar com uma pirimidina. No DNA, uma adenina sempre se complementará com uma timina enquanto que uma citosina sempre se ligará com uma guanina ${ }^{13}$.

A ligação entre bases púricas e pirimídicas pode ser mais ou menos forte dependendo de qual base está envolvida. Duas pontes de hidrogênio se formam entre a adenina e a timina $(A=T)$, enquanto três pontes se formam entre a citosina e a Guanina $(\mathrm{G} \equiv \mathrm{C})^{10}$. A ribose faz um elo entre o fosfato e a base em cada nucleotídeo (Figura 2).

A sequência de diferentes nucleotídeos no DNA forma códigos para produzir moléculas funcionais para as células, RNA e proteínas, assim como um livro de receitas possui instruções para o preparo de diferentes alimentos. Cada sequência instrutiva é denominada gene. Os genes se encontram dispostos linearmente na molécula de DNA e possuem um local definido no cromossomo, o lócus gênico (plural: loci) ${ }^{13}$. Sendo assim, cada cromossomo contém uma sequência específica de genes (Figura 3).

O gene é a unidade de informação genética. Molecularmente isso se traduz por uma sequência especifica de nucleotídeos. A estrutura do gene compreende diferentes regiões definidas como: região reguladora, região promotora, região codificante dividida em exons e introns e, região terminadora (Figura 4). As regiões reguladoras e promotoras permitem que o gene seja transcrito no momento preciso por um período determinado. A região promotora também indica para as enzimas específicas a posição do nucleotídeo que inicia a região codificante. Similarmente, a região terminadora assinala o final da informação que deve ser transcrita ${ }^{10}$.

O produto da transcrição é o RNA, uma molécula de fita simples formada por nucleotídeos cujo açúcar é a ribose. Assim, a molécula de RNA representa um intermediário entre a informação contida no DNA, e a execução (tradução) desta informação em forma de proteína ${ }^{10}$ (Figura 5).

As sequências que darão origem às proteínas serão somente aquelas dos exons (Figura 4). Os introns, por sua vez, são compreendidos como fragmentos dos genes que, embora sejam transcritos no RNA no núcleo, não são traduzidos em proteína no citoplasma ${ }^{13}$. Isso se deve ao fato de que, ainda no interior do núcleo, as regiões de RNA derivadas de sequências intrônicas são retiradas antes de sua passagem para o citoplasma pelo processamento do RNA primário (splicing), que se deve a ação de enzimas que clivam o RNA recém transcrito nas regiões onde as sequências de exons se encontram com as de introns e, posteriormente, reúne apenas as sequências exoneras, gerando o RNA maduro ${ }^{10}$ (Figura 4).

Modificações na sequência do nucleotídeo de um gene são conhecidas como mutações. Mutações ocorrem constantemente, tanto por eventos intracelulares, tais como por ação de radicais livres produzidos em processos celulares, quanto devido a eventos ambientais, tais como os raios ultravioletas. 
Figura 3. Esquema mostrando relação entre cromossomos, DNA e genes.
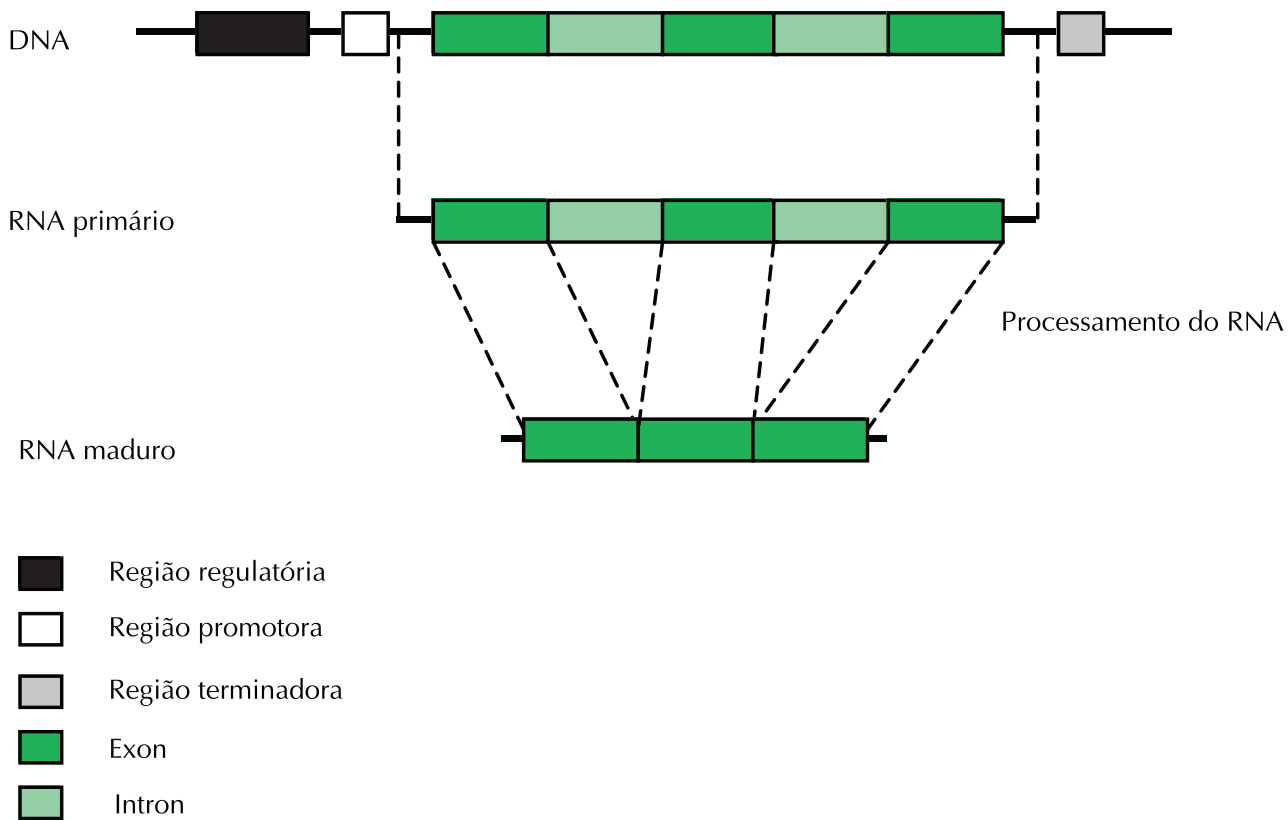

Figura 4. Estrutura de um gene. A formação do RNA primário sofre maturação antes de ser exportado para o citoplasma onde será traduzido em proteína.

As células possuem mecanismos diversos para corrigir a introdução de erros na sequência de DNA, porém, quando estes mecanismos falham a mutação é fixada. Existem vários tipos de lesões ou mutações, desde substituição de uma simples base até deleções e inserções de grandes sequências nucleotídicas ${ }^{14}$. Nesta revisão, serão evidenciadas apenas as substituições simples, ou variação de um só nucleotídeo (SNP) em uma determinada sequência gênica.

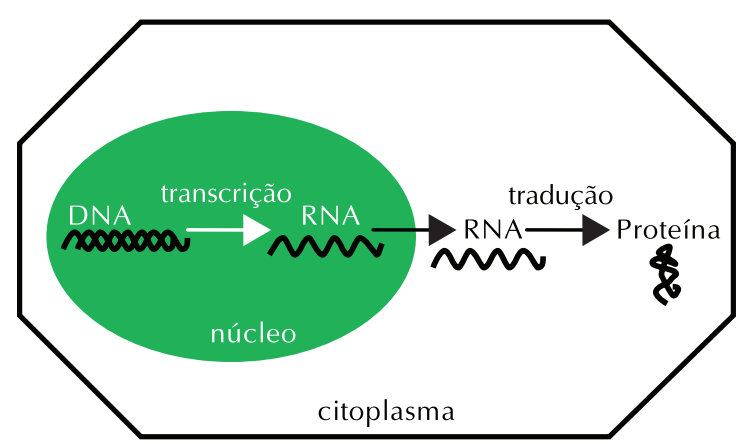

Figura 5. Dogma da biologia molecular. Fluxo da informação, do DNA contido no núcleo das células (informação) à execução desta informação em forma de proteína no citoplasma, graças à passagem por um intermediário (RNA).
Do ponto de vista evolutivo, a principal consequência das mutações é o aumento da variabilidade. Visto isso, as mutações podem tanto ser benéficas quanto maléficas, no sentido de que tanto podem contribuir com uma adaptação positiva, quanto gerar defeitos que comprometem a existência do indivíduo. Quando uma mutação se encontra presente em uma população, em uma frequência superior a $1 \%$, denomina-se de polimorfismo ${ }^{14,15}$. $\mathrm{O}$ gene inicial possui, então, uma forma não modificada e uma modificada (polimórfica). As diferentes formas de uma mesma informação genética são chamadas de alelo ${ }^{13}$.

Em organismos de reprodução sexuada, o zigoto (2n) é constituído por um conjunto de informações proveniente do genitor masculino (n) e do feminino (n). Sendo assim, os humanos possuem duas cópias de cada gene. Se, no lócus A, as formas do gene A, herdadas do pai e da mãe, são idênticas, o individuo é homozigoto para o lócus $\mathrm{A}$. Se as formas do gene A são diferentes (Aa), o indivíduo é heterozigoto para o gene $A^{10}$. Isso pode ser causado devido a um SNP no gene, ou a mutações mais consequentes. Num indivíduo heterozigoto, o alelo que determina 
qual das variações de uma característica é expressa, é chamado de dominante, o outro, que só se expressa em homozigose, é o alelo recessivo ${ }^{15}$.

Assim, as características físicas de um indivíduo dependem do conjunto de informação genética, herdada de cada genitor (genótipo). Porém, a expressão deste genótipo dependerá da interação das diferentes formas de uma mesma informação e da ação do meio ambiente (fenótipo). Logo, um dos desafios da genética é identificar quais variações nucleotídicas estão relacionadas a manifestações de fenótipos patológicos ${ }^{16}$.

\section{Generalidades do gene FTO e do rs9939609} Inicialmente, o gene FTO foi descoberto em camundongos e recebeu o nome de FT (do inglês: fused toes), devido a estes terem os dedos unidos. Essa mutação ocorre por uma série de deleções nos nucleotídeos do gene FT, que está no cromossomo 8 dos camundongos, o qual é homólogo ao cromossomo $16 \mathrm{em}$ seres humanos ${ }^{17}$. Posteriormente, este gene foi clonado e percebeu-se o seu grande tamanho (502 aminoácidos). Por isso, foi apelidado de Fatso (gordinho) e abreviado para Fto ${ }^{18}$. Somente com a descoberta da relação deste gene com o acúmulo excessivo de gordura corporal é que a Human Genome Organisation (Gene Nomenclature Committee) mudou o nome do gene de Fto para fat mass and obesity associated, porém mantendo a sigla $\mathrm{FTO}^{19}$.

A função exata do gene FTO ainda não foi elucidada. Em camundongos e em humanos encontrou-se uma alta expressão deste gene no cérebro, especificamente, no núcleo arqueado e no hipotálamo, cuja regulação é promovida pelo jejum $^{20,21}$. Isto sugere um possível papel no controle da homeostase energética, com o produto do FTO atuando como regulador primário do acúmulo de gordura corporal ${ }^{20}$. Relevante expressão do gene FTO também foi encontrada no tecido adiposo, pâncreas, fígado ${ }^{21}$, musculatura esquelética estriada e cardíaca, rins, gônadas, entre outros ${ }^{20,21}$. Ainda não foi identificada a estrutura da proteína que este gene expressa, nem foi encontrada nenhuma ligação com outras proteínas conhecidas ${ }^{22}$. Até o momento, isto impossibilita identificar a dimensão de atuação deste gene em cada tecido.

$\mathrm{O}$ gene FTO encontra-se na região cromossômica 16 q12.2, possui 9 exons e 8 introns, num total de $2.348 \mathrm{SNPs}^{23}$. Destes SNPs, 92 têm conhecida importância científica, dos quais 26 estão relacionados com o IMC ${ }^{24}$. O SNP rs9939609 encontrase no intron 1 do gene FTO. Este SNP vem sendo estudado com maior frequência, porque apresenta maior sucesso na taxa de genotipagem (100\%) e possibilita associações com menores chances de erro? É constituído por dois alelos - A e T. O alelo A está diretamente relacionado a um maior acúmulo de gordura corporal, principalmente, quando se apresenta na forma homozigota (AA) $)^{7,20,22,24,25}$.

\section{Relação entre o rs9939609 e o fenótipo da gordura}

Frayling et al. ${ }^{7}$ pesquisaram uma amostra de 38.759 voluntários europeus e encontraram uma frequência de $16 \%$ de indivíduos homozigotos A para o SNP rs9939609 do gene FTO. Este grupo alélico entrou no modelo de regressão logística com uma probabilidade, aproximadamente, 1,2 vezes maior de apresentar sobrepeso (IMC $\geq 25 \mathrm{~kg} / \mathrm{m}^{2}$ ) ou 1,3 vezes maior de apresentar obesidade (IMC $\geq 30 \mathrm{~kg} /$ $\mathrm{m}^{2}$ ). Apesar do IMC ter sido a única variável que entrou no modelo de regressão, em média, aqueles classificados como obesos apresentaram maior circunferência de cintura e maior espessura de dobras cutâneas, o que demonstra uma maior quantidade de gordura corporal nestes indivíduos.

Adultos e crianças $(\mathrm{n}=2.900)$ de ancestralidade europeia, homozigotos A para o SNP rs9939609, do gene FTO, apresentaram $22 \%$ a mais de chance em ter obesidade severa ${ }^{22}$. Os adultos de ambos os sexos, portadores dos alelos TT (homozigotos T) para o rs9939609 são, em média, $3 \mathrm{~kg}$ mais leves que os homozigotos $\mathrm{A}$, e $1,5 \mathrm{~kg}$ mais leves que os heterozigotos $(\mathrm{AT})^{7,22}$. Isto indica que os homozigotos $\mathrm{T}$ apresentam uma menor massa corporal. Para cada cópia do alelo A que o indivíduo possui, geralmente, corresponde a um aumento de $0,4 \mathrm{~kg} /$ $\mathrm{m}^{2}$ no IMC. Outros pesquisadores ${ }^{25,26}$ encontraram associação entre a presença dos alelos AA e a manifestação de uma maior quantidade de gordura corporal relativa $(\mathrm{G} \%)$. Resultados diferentes foram encontrados ${ }^{27}$ em populações de ilhas oceânicas (Malásia, Micronésia e Polinésia). Dos 320 voluntários, aproximadamente, $73 \%$ eram obesos (IMC $\geq 30 \mathrm{~kg} / \mathrm{m}^{2}$ ). Não foi encontrada nenhuma relação entre os alelos AA, AT ou TT com a presença de obesidade. Os autores sugerem que talvez outro polimorfismo do gene FTO seja mais atuante nesta população. Também observou-se que a frequência de indivíduos homozigotos A estava entre 1\% e $12,5 \%$, dependendo da amostra de cada ilha, a qual está, em média, bem inferior a encontrada no estudo de Frayling et al .

Associação direta entre os alelos AA e a quantidade de massa gorda (medida por absortometria de 
raio X de dupla energia - AXDE) foi obtida noutro estudo $^{25}$. Os indivíduos homozigotos para o alelo A têm aproximadamente 1,3 vezes mais chances de apresentar uma elevação de $10 \mathrm{~kg}$ de massa gorda em relação aos portadores do genótipo TT. Este resultado persistiu mesmo após o ajuste para a quantidade de massa livre de gordura.

Ao ser pesquisado se recém nascidos de ambos os sexos $(n=234)$ apresentariam diferenças significativas na gordura corporal, ao nascer, de acordo com a presença do alelo $A$, nenhum resultado significativo foi encontrado ${ }^{28}$. Os bebês foram reavaliados após 13 dias de vida. Os homozigotos para o alelo $\mathrm{A}$ apresentaram maior ganho de massa gorda (estimada nas duas ocasiões por AXDE). Os bebês AA apresentaram 20\% e $17 \%$ a mais de gordura no tronco e de $\mathrm{G} \%$, respectivamente, do que os bebês TT. Esta evidência corrobora os resultados de outra pesquisa $^{25}$, reforçando o status do rs9939609 como fator de predisposição genética para o acúmulo excessivo de gordura.

Ainda não se sabe ao certo como o alelo A, presente no SNP rs9939609, pode influenciar um maior acúmulo de gordura corporal ${ }^{7,26,29}$. Supõe-se que devido a sua alta expressão no hipotálamo, região que está diretamente ligada ao controle do apetite e ao acúmulo de gordura corporal, ocorre uma estimulação dessa região cerebral para poupar os estoques de gordura corporal. Isso pode ocorrer a partir da diminuição da saciedade e/ou do aumento da capacidade de captação de gordura pelos adipócitos? ${ }^{7}$. No hipotálamo, o FTO pode catalisar a retirada do radical metil $\left(\mathrm{CH}_{3}\right)$ do gene (demetilação dos ácidos nucléicos), promovendo uma maior expressão de RNAm. Este carrega a informação da proteína que deve ser sintetizada ${ }^{20}$. Isto indica que o gene FTO, nesta situação, estaria mais atuante na promoção do acúmulo excessivo de gordura.

\section{Influência do estilo de vida sobre o rs9939609 e o fenótipo da gordura}

Além do componente genético, mais fatores afetam potencialmente o desenvolvimento da obesidade ${ }^{30}$, os hábitos alimentares, o gasto energético diário, o uso de medicamentos entre outros. A variabilidade de tais fatores dificulta a determinação da influência de SNPs sobre uma característica específica.

Em indivíduos $(\mathrm{n}=704)$ norte-americanos, do meio rural, que consomem apenas o que plantam ou criam, foram pesquisados 26 SNPs do gene FTO, os quais apresentaram relação com o IMC em outros estudos $^{24}$. O rs9939609 não apresentou associação com o IMC, no entanto, associou-se com a G\% estimada pela AXDE, em uma sub-amostra de 355 indivíduos. A prevalência de sobrepeso e obesidade (IMC), nos homens, foi de $54,0 \%$ e $10,1 \%$, e nas mulheres, foi de $63,7 \%$ e $30,5 \%$, respectivamente. Quando a amostra foi separada de acordo com o nível de atividade física, nos mais fisicamente ativos não foi encontrada associação entre nenhum dos SNPs pesquisados e elevações no IMC, circunferência de cintura ou G\% (AXDE). Os autores enfatizam uma moderada à forte ação da atividade física sobre uma possível atuação no acúmulo de gordura decorrente dos SNPs do FTO.

O SNP rs9939609 foi genotipado em 17.508 dinamarqueses ${ }^{31}$. Estes foram divididos em fisicamente ativos e inativos. Foi constatado que os homozigotos $\mathrm{A}$, fisicamente inativos, apresentavam, em média, $1,95 \pm 0,3 \mathrm{~kg} / \mathrm{m}^{2}(\mathrm{p}=0,007)$ a mais de IMC do que os homozigotos T. Entre os indivíduos fisicamente ativos não houve diferença significante para o IMC entre os grupos alélicos A e T. Tal resultado enfatiza a atividade física como um fator protetor contra o acúmulo de gordura corporal, superando a predisposição genética (AA).

Em Gâmbia foram colhidos os dados de 2.164 indivíduos adultos. A maioria tinha a agricultura como forma de subsistência e eram predominantemente magros (IMC $\left.<25 \mathrm{~kg} / \mathrm{m}^{2}\right)$. Nenhuma associação foi encontrada entre os alelos $\mathrm{A}$ ou $\mathrm{T}$ do rs9939609 e o IMC. Os pesquisadores ${ }^{32}$ ressaltam que, antes de considerar os efeitos do estilo de vida para esta amostra, devem ser levadas em consideração as grandes carências nutricionais que muitos sofreram durante a vida, além das inúmeras doenças infecto-contagiosas a que estiveram expostos.

Foi verificada a influência dos alelos do rs9939609 e da dieta hipercalórica sobre a massa gorda (medida por AXDE) de 2.275 adolescentes, mensurados aos 10 e aos 13 anos de idade ${ }^{29}$. Os portadores de alelos AT e AA estavam com $0,71 \pm 0,16 \mathrm{~kg}$ e $1,42 \pm 0,32 \mathrm{~kg}$, respectivamente, a mais de massa gorda do que os homozigotos T. Para cada $0,24 \mathrm{kcal} / \mathrm{g}$, aumentada na dieta no período de 3 anos, houve um acúmulo de 0,24 $\pm 0,07 \mathrm{~kg}$ de massa gorda. Concluiu-se que os adolescentes que possuem uma dieta com maior densidade energética e são homozigotas A, apresentam maior $G \%$, divergente dos portadores de alelos TT ou AT com a mesma dieta.

Pessoas portadoras dos alelos AA apresentam reduzida resposta de saciedade ${ }^{33}$. Isto foi concluído após a comparação de 3.337 ingleses com idade média de 10,7 \pm 2 ,7anos, divididos nos três grupos alélicos (AA, AT e TT). Cecil et al. ${ }^{26}$ não obser- 
varam a mesma relação com crianças entre 4 e 10 anos de idade. Porém, perceberam que os homozigotos A têm piores escolhas alimentares que os demais. Isto indica uma possível ação hiperfágica desse gene, ou seja, desenvolve-se uma postura de consumir, preferencialmente, alimentos com alta densidade energética.

\section{Associação do rs9939609 com co-morbidades}

Atenção especial tem sido dada ao SNP rs9939609, devido à maior ocorrência de relação de seus alelos com o acúmulo excessivo de gordura ${ }^{27,34}$. A importância de se detectar a relação do rs9939609 e de outros SNPs, com o desenvolvimento da obesidade, vem do fato de que várias doenças crônicas nãotransmissíveis têm sua instalação facilitada quando há um excesso de gordura corporal ${ }^{3}$. As co-morbidades associadas, mais comuns, são o diabetes tipo $\mathrm{II}^{7}$, algumas formas de doenças cardiovasculares ${ }^{35}$, síndrome metabólica ${ }^{36}$, entre outras.

Inicialmente, pesquisas em camundongos levantaram suspeitas da existência de associação entre o SNP rs9939609 e o diabetes tipo I. Baseados nisso, Field et al. ${ }^{34}$ pesquisaram a presença deste polimorfismo em 14.803 britânicos, adolescentes e adultos. Encontraram uma frequência de $16 \%$ para os alelos AA, não encontrando associação com o diabetes tipo I e sim com o tipo II. O diabetes tipo II é uma co-morbidade que se instala na presença de uma alimentação rica em açúcares simples? . Geralmente, uma alimentação inadequada leva ao acúmulo excessivo de gordura e ao desenvolvimento do diabetes tipo II ${ }^{34}$. Resultados semelhantes foram encontrados em estudo longitudinal, conduzido por 15 anos, em 2.230 finlandeses caucasianos. Os sujeitos com alelos AA apresentaram maior predisposição para o acúmulo excessivo de gordura e de diabetes tipo II.

O diabetes tipo II é entendido como uma consequência do processo de desenvolvimento da obesidade $^{35}$. Também foi encontrada relação da presença do alelo A do rs 9939609 com o decréscimo da sensibilidade à insulina e, com menores concentrações de lipoproteínas de alta densidade ${ }^{37}$. Porém, tal fato ocorreu predominantemente em indivíduos sedentários e com excesso de gordura corporal.

Não foi encontrada nenhuma associação entre variáveis metabólicas de risco cardiovascular (níveis séricos de glicose, triglicérides, colesterol total e suas frações) com o SNP rs9939609, em 519 jovens de origem alemã, com idade média de $10,7 \pm 3,1$ anos $^{38}$, mas os homozigotos A apresentavam maior IMC. Deste grupo foi selecionada uma sub-amostra de 207 jovens obesos, os quais receberam uma intervenção (12 semanas) de mudança no estilo de vida, com fins de emagrecimento. Não foi encontrada, entre os grupos alélicos (AA, AT e TT), nenhuma diferença significante em relação às variáveis metabólicas mensuradas. Associações com elevações ocorridas nas lipoproteínas de baixa densidade e com algumas manifestações de doenças cardíacas só foram encontradas para outro SNP (rs599839) do gene $\mathrm{FTO}^{39}$. Na análise de associação do SNP rs9939609, com 10 marcadores da síndrome metabólica, em 17.037 europeus ${ }^{40}$, somente 4 marcadores se mostraram associados à presença dos alelos AA: elevadas concentrações de insulina, glicose, triglicérides e reduzidas concentrações de lipoproteínas de alta densidade. Apesar de ter sido estimado um risco 1,27 vezes maior de indivíduos AA apresentarem diabetes tipo II. O mecanismo pelo qual isto ocorre não foi identificado.

O rs9939609 foi pesquisado em uma população não-caucasiana $(n=2.121)$, descendentes de chineses residentes no Canadá e esquimós da Groelândia. Observou-se uma forte associação inversa dos alelos AA com as lipoproteínas de alta densidade e uma associação positiva com a circunferência de cintura. Não é possível afirmar que o rs9939609 é o responsável direto pelas baixas concentrações de lipoproteínas de alta densidade nos homozigotos $\mathrm{A}^{36}$. Isto pode ser, simplesmente, o reflexo de um baixo nível de atividade física mais a possibilidade de algum outro componente genético específico estar influenciando a reduzida síntese desta lipoproteína.

Hipotetizando que o excesso de gordura corporal também poderia estar coligado à morbidade e mortalidade do sistema nervoso periférico, Zimmermann et al. ${ }^{41}$ pesquisaram dois grupos de homens. Um grupo de obesos $(n=752)$ e outro de não obesos ( $n=$ 876), os quais foram acompanhados por 13,5 anos, período no qual ocorreram 205 mortes. Os resultados encontrados indicaram que os portadores de alelo A (homozigotos ou heterozigotos) foram mais propensos à mortalidade pelos efeitos do tabagismo do que os homozigotos $\mathrm{T}$, independente de ser obeso ou não. Nenhum dos alelos do rs9939609 apresentou qualquer influência sobre o sistema nervoso.

Como o diabetes tipo II é desenvolvido, principalmente, devido a maus hábitos alimentares adquiridos ao longo da vida, os indivíduos homozigotos A possuem maior facilidade para acumular gordura corporal. Consequentemente, estão mais propensos a desenvolver esta patologia. Este processo, também, pode conduzir a elevações nas concentrações de lipídios sanguíneos (triglicérides, colesterol total e 
lipoproteínas de baixa densidade). As baixas concentrações de lipoproteínas de alta densidade podem estar sendo mais influenciadas pelo baixo nível de atividade física do que pelo SNP rs9939609.

\section{CONSIDERAÇÕES FINAIS}

Caucasianos, homozigotos A para o SNP rs9939609, apresentaram maior susceptibilidade ao acúmulo excessivo de gordura corporal. A influência deste alelo foi menos expressiva em sujeitos de etnia não-caucasiana, fisicamente ativos, ou que foram expostos a grandes privações calórico/protéicas. Os homozigotos $\mathrm{A}$, também, podem apresentar menor resposta à saciedade e costumam fazer escolhas por alimentos com maior densidade energética. A maior facilidade para o acúmulo de gordura corporal dos homozigotos $\mathrm{A}$, mais a redução na percepção da saciedade, podem ser um agente facilitador para a instalação de co-morbidades que se desenvolvem concomitantemente à obesidade, como o diabetes tipo II, a piora do perfil lipídico sanguíneo e o conseqente desenvolvimento de doenças cardiovasculares.

A convergência das evidências expostas indica que a obesidade é de origem multifatorial, com forte influência do estilo de vida, o qual pode colocar pessoas portadoras do alelo A, para o SNP rs9939609, em condições mais favoráveis para o acúmulo excessivo de massa gorda. No entanto, a atividade física atua como fator protetor para indivíduos AA e AT. Sendo assim, encorajamento para um estilo de vida saudável deve ser oferecido a todas as pessoas, independente de estas serem, ou não, portadoras do alelo A para o SNP rs9939609, do gene FTO.

Parece que as doenças crônicas não-transmissíveis, associadas ao excesso de gordura corporal, estão mais condicionadas ao tipo de estilo de vida, que potencializa a obesidade, do que ao SNP rs9939609. No entanto, é necessário pesquisar diferentes etnias e miscigenações, levando em consideração as diversas variáveis que compõem o estilo de vida e que parecem ter o poder, em alguns casos, de minimizar a ação do fator genético. Estudos com estas variáveis, feitos com amostras brasileiras, são desconhecidos.

\section{REFERÊNCIAS BIBLIOGRÁFICAS}

1. World Health Organization. Obesity: preventing and managing the global epidemic. Geneva: World Health Organization; 2000. (WHO technical report series, v. 894).
2. Glaner MF. Tendência secular do crescimento físico e índice de massa corporal em escolares. R Min Educ Fís 1998;(6)2:59-69.

3. Hill JO. Can a small-changes approach help address the obesity epidemic? A report of the Joint Task Force of the American Society for Nutrition, Institute of Food Technologists, and International Food Information Council. Am J Clin Nutr 2009;89(2):477-484.

4. Hill JO. Understanding and addressing the epidemic of obesity: an energy balance perspective. Endocr Rev 2006;27(7):750-761.

5. Lima WA, Glaner MF. Body fat topography as a predictor of an increase in blood lipids. RBM Rev Bras Med 2009;66(supl especial):3-9.

6. Poirier P, Giles TD, Bray GA, Hong Y, Stern JS, PiSunyer FX, et al. Obesity and cardiovascular disease: pathophysiology, evaluation, and effect of weight loss. Arterioscler Thromb Vasc Biol 2006;26(5):968-976.

7. Frayling TM, Timpson NJ, Weedon MN, Zeggini E, Freathy RM, Lindgren CM, et al. A common variant in the fto gene is associated with body mass index and predisposes to childhood and adult obesity. Science 2007;316(5826):889-894.

8. Fisler JS, Warden CH. The current and future search for obesity genes. Am J Clin Nutr 2007;85(1):1-2.

9. Kumanyika SK, Obarzanek E, Stettler N, Bell R, Field AE, Fortmann SP, et al. Population-based prevention of obesity: the need for comprehensive promotion of healthful eating, physical activity, and energy balance: a scientific statement from American Heart Association council on epidemiology and prevention, interdisciplinary committee for prevention (Formerly the Expert Panel on Population and Prevention Science). Circulation 2008;118(4):428- 464.

10. Griffiths AJF, Wessler SR, Lewontin RC, Carroll SB. Introdução à genética. 9. ed. Rio de Janeiro: Guanabara Koogan; 2008.

11. Centro de referência virtual do professor. Linguagens da vida - organização celular: Brasil. 2009; Available from: <http://crv.educacao.mg.gov.br/sistema_crv/ index. asp?id_projeto=27\&ID_OBJETO=61827\& tipo $=\mathrm{ob} \& \mathrm{cp}=000000 \& \mathrm{cb}=>$ [2009 Oct 26].

12. Cosgrove M. Nucleotides. Nutrition 1998;14(10):748-751.

13. Calafell F, Malats N. Basic molecular genetics for epidemiologists. J Epidemiol Community Health 2003;57(6):398-400.

14. Maki H. Origins of spontaneous mutations: specificity and directionality of base-substitution, frameshift, and sequence-substitution mutageneses. Annu Rev Genet 2002;36(1):279-303.

15. The Human Genome. Mutation or polymorphism: London. 2003; Available from: <http:/genome.wellcome.ac.uk/doc_WTD020780.html> [2009 Oct 22].

16. Brookes AJ. The essence of SNPs. Gene 1999;234(2):177186.

17. van der Hoeven F, Schimmang T, Volkmann A, Mattei MG, Kyewski B, Ruther U. Programmed cell death is affected in the novel mouse mutant Fused toes $(\mathrm{Ft})$. Development 1994;120(9):2601-2607. 
18. Peters T, Ausmeier K, Rüther U. Cloning of fatso (Fto), a novel gene deleted by de fused toes $(\mathrm{Ft})$ mouse mutation. Mamm Genome 1999;10(10):983-986.

19. Fredriksson R, Hagglund M, Olszewski PK, Stephansson O, Jacobsson JA, Agnieszka M, et al. The obesity gene, FTO, is of ancient origin, up-regulated during food deprivation and expressed in neurons of feeding-related nuclei of the brain. Endocrinology 2008;149(5):2062-2071.

20. Gerken T, Girard CA, Tung YL, Webby CJ, Saudek V, Hewitson KS, et al. The obesity-associated FTO gene encodes a 2-oxoglutarate-dependent nucleic acid demethylase. Science 2007;318(5855):1469-1472.

21. Stratigopoulos G, Padilla SL, LeDuc CA, Watson E, Hattersley AT, McCarthy MI, et al. Regulation of Fto/ Ftm gene expression in mice and humans. Am J Physiol Regul Integr Comp Physiol 2008;294(4):R1185-R1196.

22. Dina C, Meyre D, Gallina S, Durand E, Körner A, Jacobson P, et al. Variation in FTO contributes to childhood obesity and severe adult obesity. Nat Genet 2007;39(6):724-726.

23. National Center for Biotechnology Information/ NCBI. Fat mass and obesity associated: United States. 2009; Available from: <http://www.genecards.org/ cgi-bin/carddisp.pl?search $=24678 \&$ id $=24678 \&$ id_ type $=$ hgnc\& $\&$ snp $=2348 \#$ snp $>$ [2009 Oct 22].

24. Rampersaud E, Mitchell BD, Pollin TI, Fu M, Shen H, O'Connell JR, et al. Physical activity and the association of common gene FTO variants with body mass index and obesity. Ach Inter Med 2008;168(16):1791-1797.

25. Berentzen T, Kring SII, Holst C, Zimmermann E, Jess T, Hansen T, et al. Lack of association of fatness-related FTO gene variants with energy expenditure or physical activity. J Clin Endocrin Metab 2008;93(7):2904-2908.

26. Cecil JE, Tavendale R, Watt P, Hetherington MM, Palmer CN. An obesity-associated FTO gene variant and increased energy intake in children. N Engl J Med 2008;359(24):2558-2566

27. Ohashi J, Nakka I, Kimura R, Natsuhara K, Yamauchi $\mathrm{T}$, Furusawa T, et al. FTO polymorphisms in oceanic populations. J Hum Genet 2007;52(12):1031-1035.

28. López-Bernejo F, Petry Cj, Días M, Sebastiani G, Zegher F, Dunger Db, et al. The association between the FTO gene and fat mass in humans develops by the postnatal age of two weeks. J Clin Endocrin Metab 2008;93(4):1501-1505.

29. Jonsson A, Renström F, Lyssenko V, Brito EC, Isomaa B, Berglund G, et al. Assessing the effect of interaction between an FTO variant (rs9939609) and physical activity on obesity in 15,925 Swedish and 2,511 Finnish adults. Diabetologia 2009;52(7):1334-1338.

30. Aisbitt B. Obesity - should we blame our genes? $\mathrm{Nu}$ trition Bulletin 2007;32(3):183-186.

31. Andreasen $\mathrm{CH}$, Stender-Petersen, KL, Mongensen MS, Torekov SS, Wegner L, Andersen, G, et al. Low physical activity accentuates the effect of the FTO rs9939609 polymorphism on body fat accumulation. Diabetes 2008;57(1),95-101.

32. Hennig BJ, Fulford AJ, Sirugo G, Rayco-Solon P, Hattersley AT, Frayling TM, et al. FTO gene variation and measures of body mass in an African population. BMC Med Genet 2009;10(22):21-28.

33. Wardle J, Carnell S, Haworth CM, Farooqi IS, O'Rahilly S, Plomin R. Obesity associated genetic variation in FTO is associated with diminished satiety. J Clin Endocrinal Metab 2008;93(9):3640-3643.

34. Field SF, Howson JMM, Walker NM, Dunger db, Todd JA. Analysis of the obesity gene FTO in 14,803 type 1 diabetes cases and controls. Diabetologia 2007;50(10):2218-2220.

35. Kivimäki M, Smith GD, Timpson NJ, Lawlor DA, Batty GD, Kähönen M, et al. Lifetime body mass index and later atherosclerosis risk in young adults: examining causal links using mendelian randomization in the cardiovascular risk in young finns study. Eur Heart J 2008;29(20):2552-2560.

36. Al-Alttar SA, Pollex R1, Ban MR, Young TK, Bjerregaard P, Anand SS, et al. Association between the FTO rs9939609 polymorphism and the metabolic syndrome in a non-caucasian multi-ethinic sample. Cardiovasc Diabetol 2008;7(5).

37. Kring SII, Holst C, Zimmermann E, Jess T, Berentzen T, Toubro S, et al. FTO gene associated fatness in relation to body fat distribution and metabolic traits throughout a broad range of fatness. PLoS ONE 2008;3(8):e2958.

38. Müller TD, Hinney A, Scherag A, Nguyen TT, Schreiner F, Schäfer, H, et al. 'Fat mass and obesity associated' (FTO): no significant associated of variant rs9939609 with weight loss in a lifestyle intervention and lipid metabolism markers in German obese children and adolescents. BMC Med Genet 2008;9(85):85-90.

39. Ioannidis JPA. Prediction of cardiovascular disease outcomes and established cardiovascular risk factors by genome-wide association markers. Circ Cardiovasc Genet 2009;2(1):7-15.

40. Freathy RM, Timpson NJ, Lawlor DA, Pouta A, BenShlomo Y, Ruokomen A, et al. Common variation in the FTO gene alters diabetes-related metabolic traits to the extent expected given its effect on BMI. Diabetes 2008;57(5):1419-1426.

41. Zimmermann E, Kruing S, Berentzen T, Holst C, Pers TH, Hansen T, et al. Fatness-associated FTO gene variant increases mortality independent of fatness - in cohorts of Danish men. PLoS ONE 2008;4(2):e4428.

\section{Agradecimento}

Os autores agradecem ao apoio do $\mathrm{CNPq}-$ processo $n^{\circ}$. 481859/2007
Endereço para correspondência
Maria Fátima Glaner
Q 201, Lt 6, Bl B - apt. 803
CEP 71937-540 - Águas Claras, Brasília - DF
E-mail-mfglaner@gmail.com 